\title{
Pregnancy in Adolescents at Peripheral Care Unit Gbodjome (Togo): Epidemiological Aspects and Causes
}

\author{
Ameyo Ayoko Ketevi1*, Yvon Foli Agbeko², Dede Regine Diane Ajavon ${ }^{3}$, Baguilane Douaguibe1, \\ Akila Bassowa4 ${ }^{4}$ Assiaham Walawita Tenete', Kossi Edem Logbo-Akey5, \\ Akossiwa Adeline Gloria Djankale ${ }^{1}$, Nagbe Massogblé Kodjo Koffi ${ }^{1}$, Kodjo Fiagnon ${ }^{1}$, \\ Abdoul-Samadou Aboubakari 5
}

\footnotetext{
${ }^{1}$ Department of Gynecology and Obstetrics, Sylvanus Olympio Teaching Hospital, Lome, Togo

${ }^{2}$ Department of Pediatrics, Campus Teaching Hospital, Lome, Togo

${ }^{3}$ Department of Gynecology and Obstetrics, Regional Hospital center, Kara, Togo

${ }^{4}$ Department of Gynecology and Obstetrics, Campus Teaching Hospital, Lome, Togo

${ }^{5}$ Department of Gynecology and Obstetrics, Kara Teaching Hospital, Kara, Togo

Email: ^tketevi@yahoo.fr
}

How to cite this paper: Ketevi, A.A., Agbeko, Y.F., Ajavon, D.R.D., Douaguibe, B., Bassowa, A., Tenete, A.W., Logbo-Akey, K.E., Djankale, A.A.G., Koffi, N.M.K., Fiagnon, K. and Aboubakari, A.-S. (2020) Pregnancy in Adolescents at Peripheral Care Unit Gbodjome (Togo): Epidemiological Aspects and Causes. Open Access Library Journal, 7: e6873.

https://doi.org/10.4236/oalib.1106873

Received: September 29, 2020

Accepted: November 9, 2020

Published: November 12, 2020

Copyright $\odot 2020$ by author(s) and Open Access Library Inc.

This work is licensed under the Creative Commons Attribution International License (CC BY 4.0).

http://creativecommons.org/licenses/by/4.0/ (c) (i) Open Access

\begin{abstract}
Introduction: Teenage pregnancies have serious consequences for the health of mothers and their children. The aim of this work was to study the circumstances of the onset of teenage pregnancy. Methodology: This was a cross-sectional and descriptive study, which took place from July $1^{\text {st }}$ to $31^{\text {st }}$, 2019 at the Peripheral Care Unit (USP) of Gbodjomé in Togo. Results: A total of 100 adolescent girls were interviewed (12.6\%). The average age of adolescent girls was 17.2 years ( 12 - 19 years). Adolescent girls were predominantly in primary school (42.0\%) and single status (58.0\%). Forty-two decimal zero percent of adolescent girls (42.0\%) were living with their partners. In $5.0 \%$ of cases, adolescent girls were victims of sexual harassment. The pregnancy was the result of rape in $10.0 \%$ of cases. Ten decimal zero percent of adolescent girls $(10.0 \%)$ had more than one sexual partner. Nearly half of the respondents $(49.0 \%)$ knew at least one method of contraception, but only $8.0 \%$ used it. Financial help from the partner $(57.0 \%)$ was the leading cause of sex. Conclusion: Teenage pregnancies have a negative impact on both the young mother and the unborn child. The ideal would be to make schooling for girls free, from primary school to the A-level.
\end{abstract}

\section{Subject Areas}

Gynecology \& Obstetrics, Women's Health 


\section{Keywords}

Pregnancy, Adolescent, Togo

\section{Introduction}

Adolescent pregnancy is defined by the United Nations Children's Fund (UNICEF) as "an adolescent girl, usually between the ages of 13 and 19, who becomes pregnant and refers to girls who have not reached legal adulthood, which varies around the world" [1]. Although it is considered as a serious public health and social problem worldwide [2], about 95\% occur in developing countries [3]. For example, most adolescent pregnancies and births occur in West Africa, it is also found in Central, East and Southern Africa, South Asia, South America and the Caribbean [4]. In Togo, the birth rate among adolescents (15 19 years) was 89 births per 1000 in 2016 [5]. The causes of adolescent pregnancy are multifactorial, ranging from individual, traditional and socio-cultural behavior to religious. It is undeniable that low socioeconomic status [6] [7], limited education [8] and early sexual activity [9] can perpetuate adolescent pregnancy. In addition, increased access to social media and pornographic sharing [10], cross-cultural influences and decreased adult supervision have led to early initiation of sexual activity among adolescents [11]. It is recognized that most people begin sexual activity between the ages of 15 and 19. In low- and middle-income countries, complications of pregnancy and childbirth are the leading cause of death among women aged 15 - 19 years [12]. Young girls who become pregnant before the age of 18 are more likely to experience violence at the hands of their spouses or partners. In Togo, in 2017, the proportion of $15-19$ years old girls who became pregnant with their first child was 0.9 percent in urban areas compared to 3.5 percent in rural areas. Also, in this age group, $7.8 \%$ had a live birth in urban areas, compared to $14.5 \%$ in rural areas [13]. The aim of this work was to study the circumstances in which teenage pregnancy occurs.

\section{Patients and Method}

This was a cross-sectional and descriptive study that took place over one month (July 1-31, 2019) at the Gbodjomé Peripheral Care Unit (USP) in Togo's Lakes District, located $30 \mathrm{~km}$ far from Lomé on the east. One hundred adolescent girls aged 12 to 19 years (pregnant, parturient or in labor) who gave their free and informed consent were selected. Adolescents who did not give consent $(n=3)$ or whose clinical condition did not allow them to answer the questions $(n=2)$ were not included in the study. A direct interview, using a pre-tested questionnaire, was conducted with adolescents who came to Gbodjomé USP for prenatal consultation, vaccination, delivery, or post-partum care.

The data were processed by the software World 2010, Epi info 3.5.4 and Excel 2010. Ethically, an authorization (ref 04/2019/USP/GBO-LACS) was issued by 
the Chief Medical Officer of the Lakes District. The interview was conducted with respect and human dignity. For those who were accompanied by their parents or a guardian, or for those who came alone, a verbal, free and informed consent was obtained before the interview. The information collected was anonymous and strictly used for the purposes of our study.

\section{Results}

\subsection{Frequency}

During our survey period, 100 adolescents were interviewed out of a total of 796 admissions, a frequency of 12.6 per cent.

\subsection{Socio-Demographic Data}

The average age of adolescent girls was 17.2 with extremes of 12 and 19 years. The 15 - 19 age group was the most represented (95.0\%). They were in vocational training in $37.0 \%$ of cases. The level of education was mainly elementary school (42.0\%). They were single (58.0\%). Forty-two of the adolescents lived with their partners (Table 1).

\subsection{Causes of Pregnancy}

Two-thirds of adolescents (64.0\%) had ended their schooling well before pregnancy occurred. Both parents were alive (70.0\%). Seventy-one decimal zero percent $(71.0 \%)$ of adolescents had parents who were in the informal sector. In 5.0\% of cases, the adolescents were victims of sexual harassment. Pregnancy was the result of rape in $10.0 \%$ of cases. Adolescents had more than one partner in $10 \%$ of cases. Only $6.0 \%$ of adolescents had once heard about the consequences of early pregnancy. Forty-nine decimal zero percent (49.0\%) of adolescents knew at least one method of contraception; but only $8.0 \%$ of them used it. In just over half of cases (57.0\%), adolescents were in a sexual relationship as a result of financial assistance from their partners (Table 2).

Table 1. Distribution of adolescent girls by socio-demographic data.

\begin{tabular}{ccc}
\hline Age & Frequency & Percent (\%) \\
12 ans & 1 & 1.0 \\
13 ans & 3 & 3.0 \\
14 ans & 1 & 1.0 \\
15 ans & 9 & 9.0 \\
16 ans & 15 & 15.0 \\
17 ans & 19 & 19.0 \\
18 ans & 30 & 30.0 \\
19 ans & 22 & 22.0 \\
Total & 100 & 100.0
\end{tabular}




\section{Continued}

Occupation

Apprenticeship

Student

homemaker

Reseller

Others

Total

level of education

Uneducated

Primary

Secondary

University

Total

\section{Marital status}

$$
\text { single }
$$

Concubinage

married

Total

\section{Partner's occupation}

Craftsman
Student
Public servant
Reseller
Unknown
Total

\section{Person in cohabitation}

$\begin{array}{ccc}\text { Partner } & 42 & 42.0 \\ \text { Parents } & 32 & 32.0 \\ \text { Tutor } & 9 & 9.0 \\ \text { Grandparents } & 7 & 7.0 \\ \text { Aunt } & 6 & 6.0 \\ \text { Sister } & 3 & 3.0 \\ \text { Alone } & 3 & 3.0 \\ \text { Total } & 100 & 100.0\end{array}$

37.0

36.0

12.0

10.0

5.0

100.0

17.0

42.0

39.0

2.0

100.0

58.0

40.0

2.0

100.0

62.0

19.0

10.0

1.0

8.0

100.0

100

42.0

00.0 
Table 2. Distribution of adolescents by cause of pregnancy occurrence.

\begin{tabular}{|c|c|c|}
\hline & Frequency & Percent (\%) \\
\hline \multicolumn{3}{|l|}{ Repeating a class } \\
\hline Once & 9 & 9.0 \\
\hline Twice & 3 & 3.0 \\
\hline Never & 24 & 24.0 \\
\hline Didn't go to school & 64 & 64.0 \\
\hline Total & 100 & 100.0 \\
\hline \multicolumn{3}{|l|}{ Early cessation of studies } \\
\hline Before pregnancy & 64 & 64.0 \\
\hline After pregnancy & 36 & 36.0 \\
\hline Total & 100 & 100.0 \\
\hline \multicolumn{3}{|l|}{ Living Parents } \\
\hline Both parents alive & 70 & 70.0 \\
\hline Orphans of father and mother & 21 & 21.0 \\
\hline Orphans of father & 6 & 6.0 \\
\hline Orphans of mother & 3 & 3.0 \\
\hline Total & 100 & 100.0 \\
\hline \multicolumn{3}{|l|}{ Parents' profession } \\
\hline Non-public servants ${ }^{\star}$ (informal sector) & 71 & 71.0 \\
\hline Public servant (teacher and soldier) & 8 & 8.0 \\
\hline Others ${ }^{* *}$ & 21 & 21.0 \\
\hline Total & 100 & 100.0 \\
\hline \multicolumn{3}{|l|}{ Sexual harassment victims } \\
\hline Yes & 95 & 95.0 \\
\hline No & 5 & 5.0 \\
\hline Total & 100 & 100.0 \\
\hline \multicolumn{3}{|l|}{ Rape } \\
\hline Victims & 10 & 10.0 \\
\hline Non-victims & 90 & 90.0 \\
\hline Total & 100 & 100.0 \\
\hline \multicolumn{3}{|l|}{ Multiple partners } \\
\hline Only one partner & 90 & 90.0 \\
\hline Two partners & 7 & 7.0 \\
\hline More than two partners & 3 & 3.0 \\
\hline Total & 100 & 100.0 \\
\hline
\end{tabular}




\section{Continued}

Awareness of the consequences of pregnancy

$\begin{array}{ccc}\text { Yes } & 6 & 6.0 \\ \text { No } & 94 & 94.0 \\ \text { Total } & 100 & 100.0\end{array}$

Knowledge of contraceptive methods

$\begin{array}{ccc}\text { Yes } & 49 & 49.0 \\ \text { No } & 51 & 51.0 \\ \text { Total } & 100 & 100.0\end{array}$

Contraceptive Use

Pills $\quad 2$

Condoms

No contraceptives

\section{Factors leading to the relationship}

$\begin{array}{ccc}\text { Financial assistance } & 57 & 57.0 \\ \text { Love } & 15 & 15.0 \\ \text { Lack of parental affection } & 10 & 10.0 \\ \text { Solitude } & 8 & 8.0 \\ \text { Follow-up } & 4 & 4.0 \\ \text { Kindness of the partner } & 2 & 2.0 \\ \text { Partner pressure } & 1 & 1.0 \\ \text { Desire to have a boyfriend } & 1 & 1.0 \\ \text { Curiosity } & 1 & 1.0 \\ \text { Drunkenness } & 1 & 1.0\end{array}$

Other $^{* *}$ : cab and motorcycle cab drivers. Non-civil servant ${ }^{\star}$ : craftsman, farmer, driver, blacksmith, electrician, mason, unemployed person.

\section{Discussion}

The incidence of adolescent pregnancy was $12.6 \%$ at USP Gbodjomé in Togo. This result is similar to the national norm in 2017, when $14.5 \%$ of girls aged 15 19 had a good birth [13]. In a study conducted by Aboubakari et al. at Tsévié Hospital, $35 \mathrm{~km}$ north of Lomé, in 2013 [14], 51.8\% of adolescent girls who gave birth in the maternity ward were under 17 years of age. In Ethiopia, the national average was $13.0 \%$ among $10-19$ years old in 2016 [15]. In contrast, Habitu et al. in 2017 [16], also in Ethiopia, had higher prevalence (28.6\%). The average age of adolescent girls was 17.2. Gwido et al. in Southern Sudan in 2016, [17] reported an average age of 17.5 years. Indeed, these minors, because of their immaturity and naivety, are unable to perceive the consequences of sexual inter- 
course. It is well known that most people begin sexual activity between the ages of 15 and 19. Also, these pregnancies among minors, known as early pregnancies, have catastrophic consequences not only for the mother, but also for the child. According to the WHO, on the one hand, early pregnancy is the leading cause of death among girls aged 15 to 19 [12]. Moreover, since USP Gbodjomé is located in a rural area, the lack of recreational diversity may lead adolescents to engage in sex during their off-peak time. Added to this is the lack of financial means, so $57.0 \%$ of the adolescent girls said that they had sex for the financial help given by their partner. In addition, most of the parents were in the informal sector $(71.0 \%)$, thus having a low socioeconomic level. This exposes adolescent girls to sexual relations at an early age. Adolescent girls were mostly in primary education (42.0\%) and apprenticeships (37.0\%). Although schooling of young girls is encouraged nowadays, and government policy in Togo is such that free schooling is only offered to elementary school, much work remains to be done. In 42.0 percent of cases, adolescent girls lived with their partners. In the study by Ayele et al. in Ethiopia in 2018 [18], 55.8\% of adolescent girls lived with their husbands. In $58.0 \%$ of cases, the adolescents were unmarried. Our results are superior to those of Donatus et al. in 2008, [19] who reported 52.2\% of unmarried adolescent girls. This is justified by the fact that in our country early marriage is not allowed. Each parent wants his or her child to be autonomous and have a stable financial situation before getting married. Generally speaking, teenage pregnancy is disturbing and goes beyond current social norms. Perceived as a failure of education, it questions and worries about the future of these young mothers and the potential child to be born [20]. So it is more difficult to encourage teenage girls in a marriage project. Sixty-four point zero percent of adolescents (64.0\%) had stopped studying even well before pregnancy occurred. According to Pereira et al. [21], the onset of pregnancy in adolescence is significantly associated with more academic failure. Among the group of pregnant teens, only $12.3 \%$ were still attending classes, $52.6 \%$ had already "dropped out" before becoming pregnant. For Ochen et al. in 2019 [22], 65.0\% of pregnant adolescents were no longer attending school. In $94.0 \%$ of cases, the adolescents had never heard of the consequences of early pregnancy, and in $10.0 \%$ of cases the pregnancy was the result of rape. Despite the legalization of abortion under certain conditions in Togo in 2006 [23], parents (70.0\% had both parents alive) allowed the pregnancy to progress, either out of ignorance or religious conviction. In $92.0 \%$ of cases, no contraceptive method was used. Jewell et al. [24] found the impact of socioeconomic status on contraceptive behavior. Indeed, the low use of contraceptive methods could be explained by the fact that young people are not sufficiently informed about available services. Also, they have never experienced a pregnancy, so many are still reluctant to go to a family planning center. Another reason is that condom distribution has long been seen as a way to get young people to have sex, which has led to a more abstinence-oriented exchange between peer educators and youth. 


\section{Conclusion}

Early pregnancy is a public health problem especially in sub-Saharan Africa and particularly in rural areas. Our study evaluated its frequency among adolescents in the health area of USP Gbodjomé at $12.6 \%$. These pregnancies are, in most cases, unwanted. They occur as a result of carelessness or lack of information, financial and family support; contraceptive methods are little known and little used. These pregnancies have a harmful impact on both the young mother and the unborn child. The ideal would be to make schooling free for girls from primary school through to the Baccalaureate. In addition, the granting of monthly family allowances to the most destitute, the creation of leisure centers in rural areas and the organization of useful vacations to keep these teenage girls busy outside of school hours would go some way to help prevent the occurrence of early pregnancies.

\section{Conflicts of Interest}

The authors declare no conflicts of interest regarding the publication of this paper.

\section{References}

[1] United Nations Children's Fund (2008) The State of the World's Children 2009. Maternal and Newborn Health, UNICEF.

[2] Ganchimeg, T., Ota, E., Morisaki, N., Laopaiboon, M., Lumbiganon, P., Zhang, J., et al. (2014) Pregnancy and Childbirth Outcomes among Adolescent Mothers: A World Health Organization Multicountry Study. BJOG: An International Journal of Obstetrics \& Gynaecology, 121, 40-48. https://doi.org/10.1111/1471-0528.12630

[3] Loaiza, E. and Liang, M. (2013) Teenage Pregnancy: A Review of the Evidence. UNFPA, New York.

[4] UNFPA (2013) Motherhood in Childhood, Facing the Challenge of Adolescent Pregnancy, State of World Population.

[5] The Lancet Global Health. Countdown 2017 Report Annexes-Countdown to 2030 for Women's, Children's and Adolescents' Health. 2020. http://www.countdown2030.org/annexes

[6] Bonell, C. (2005) The Effect of Dislike of School on Risk of Teenage Pregnancy: Testing of Hypotheses Using Longitudinal Data from a Randomised Trial of Sex Education. Journal of Epidemiology \& Community Health, 59, 223-230. https://doi.org/10.1136/jech.2004.023374

[7] Vikat, A. (2002) Sociodemographic Differences in the Occurrence of Teenage Pregnancies in Finland in 1987-1998: A Follow Up Study. Journal of Epidemiology \& Community Health, 56, 659-668. https://doi.org/10.1136/jech.56.9.659

[8] Nour, N.M. (2006) Health Consequences of Child Marriage in Africa. Emerging Infectious Diseases, 12, 1644-1649. https://doi.org/10.3201/eid1211.060510

[9] Edgardh, K. (2007) Sexual Behaviour and Early Coitarche in a National Sample of 17-Year-Old Swedish Boys. Acta Paediatrica, 91, 985-991. https://doi.org/10.1111/j.1651-2227.2002.tb02889.x

[10] Joesephine, P. and Premraj, C. (2016) Adolescent Sexual and Reproductive Health. 
Global Journal for Research Analysis (GJRA), 5, 167-168.

[11] Rachakonda, L., Rawate, S. and Shiradkar, S. (2014) Teenage Pregnancy. International Journal of Current Medical and Applied Sciences, 4, 2059-2063.

[12] OMS (2012) Early Marriages, Teenage Pregnancies and Young Women. Report of the Secretariat Sixty-Fifth World Health Assembly. Genève.

[13] National Institute of Statistics and Economic and Demographic Studies (NISEDS) (2018) MICS6 TOGO, 2017. Final Report. Lome.

[14] Aboubakari, A.S., Djadou, K.E., Saka, B., Tchagbele, O.-B., Agbere, A.D., Atakouma, D.Y., et al. (2013) Childbirth among Adolescent Girls under 17 Years of Age at the Regional Hospital Center of Tsévié (Togo): An Indicator of Early Sexual Debut in Sub-Saharan Africa. SAGO Journal, 14, 17-21.

[15] Central Statistical Agency (CSA) [Ethiopia] and ICF (2016) Ethiopia Demographic and Health Survey 2016. CSA and ICF, Addis Ababa, Rockville.

[16] Habitu, Y.A., Yalew, A. and Bisetegn, T.Z. (2018) Prevalence and Factors Associated with Adolescent Pregnancy, Northeast Ethiopia, 2017: A Cross-Sectional Study. Hindawi Journal of Pregnancy, 2018, Article ID: 1714527. https://doi.org/10.1155/2018/1714527

[17] Gwido, V. and Alemu, F.M. (2016) Factors Contributing to, and Effects of, Teenage Pregnancy in Juba. South Sudan Medical Journal, 9, 28-31.

[18] Ayele, B.G., Gebregzabher, T.G., Hailu, T.T. and Assefa, B.A. (2018) Determinants of Teenage Pregnancy in Degua Tembien District, Tigray, Northern Ethiopia: A Community-Based Case-Control Study. PLoS ONE, 13, e0200898.

https://doi.org/10.1371/journal.pone.0200898

[19] Donatus, L., Sama, D.J., Tsoka-Gwegweni, J.M. and Cumber, S.N. (2018) Factors Associated with Adolescent School Girl's Pregnancy in Kumbo East Health District North West Region Cameroon. The Pan African Medical Journal, 31, 138. https://doi.org/10.11604/pamj.2018.31.138.16888

[20] Marjolaine Prieto (Cardinael) (2018) Teenage Pregnancy: Representations, Experiences and Care Practices. Human Medicine and Pathology.

[21] Pereira, A., Canavarro, M.C., Mendonça, D. and Cardoso, M.F. (2005) Relational Factors of Vulnerability and Protection for Adolescent Pregnancy: A Cross-Sectional Comparative Study of Portuguese Pregnant and Non Pregnant Adolescents of Low Socio-Economic Status. Adolescence, 40, 655-671.

[22] Ochen, A.M., Che Chi, P. and Lawoko, S. (2019) Predictors of Adolescent Pregnancy among Girls Aged 13-19 Years in Uganda: A Community-Based Case-Control Study. BCM Pregnancy and Childbirth, 19, 211. https://doi.org/10.1186/s12884-019-2347-y

[23] Gbadamassi, F. (2020) Togo Legalizes Abortion... under Certain Conditions. https://www.afrik.com/togo-legalization-abortion-undercertainconditions

[24] Jewell, D., Tacchi, J. and Donovan, J. (2000) Teenage Pregnancy: Whose Problem Is It? Family Practice, 17, 522-528. https://doi.org/10.1093/fampra/17.6.522 